Proceedings

\title{
Coral Reef Cryptic Invertebrates Across a Gradient of Coral Cover in Isla Gorgona, Eastern Tropical Pacific Off Colombia ${ }^{\dagger}$
}

\author{
Bellineth Valencia ${ }^{1, *}$ and Alan Giraldo ${ }^{2}$ \\ 1 Grupo de Investigación en Ecología de Arrecifes Coralinos, Universidad del Valle, Cali, Colombia \\ 2 Grupo de Investigación en Ecología Animal, Universidad del Valle, Cali, Colombia; \\ alan.giraldo@correounivalle.edu.co \\ * Correspondance: bellineth.valencia@correounivalle.edu.co \\ + Presented at the 1st International Electronic Conference on Biological Diversity, Ecology and Evolution, 15- \\ 31 March 2021; Available online: https://bdee2021.sciforum.net/.
}

Citation: Valencia, B.; Giraldo, A. Coral Reef Cryptic Invertebrates across A Gradient of Coral Cover in Isla Gorgona, Eastern Tropical Pacific Off Colombia. 2021, 68, x. https://doi.org/10.3390/xxxxx

Academic Editor:

Published: date

Publisher's Note: MDPI stays neutral with regard to jurisdictional claims in published maps and institutional affiliations.

Copyright: (c) 2021 by the authors. Submitted for possible open access publication under the terms and conditions of the Creative Commons Attribution (CC BY) license (http://creativecommons.org/licenses/by/4.0/).

\begin{abstract}
Coral reef micro-invertebrates are a diverse and abundant group of taxa that inhabit the reef framework structure. However, knowledge about their diversity and function is scarce, limiting our understanding of the responses of coral reef ecosystems to degradation as a whole. We investigated the variability of the cryptofauna community structure in a gradient of live coral cover in La Azufrada coral reef in Isla Gorgona, Colombian Pacific. Live coral cover was estimated from photoquadrats at 60 sampling points across the reef, where the cryptofauna were also collected in dead coral and coral rubble. We found 194 morphospecies, among which crustaceans (41\%), molluscans (24\%), and polychaetes (22\%) represented most of the species richness. The $0-25 \%, 25-50 \%$, and $50-$ $75 \%$ cover categories of live coral were similar to one another in cryptofauna species richness and abundance, but cryptofauna abundance was significantly lower in the areas of highest coral cover (75-100\%). Crustaceans were the most abundant group at all four cover categories, mainly due to high abundances of tanaidaceans and isopods. Polychaetes were more abundant in the areas of low coral cover $(<25 \%)$, whereas echinoderms, represented mostly by ophiuroids, had highest abundances at intermediate levels of coral cover (25-75\%). In contrast to abundance, echinoderms were the major contributors to cryptofauna biomass, whereas the contribution of crustaceans was relatively lower. Our results highlight the importance that substrate heterogeneity has in the maintenance of biodiversity on coral reefs.
\end{abstract}

Keywords: Coral reefs; cryptic fauna; invertebrates; Isla Gorgona; Colombia; Eastern Tropical Pacific

\section{Introduction}

Coral reefs are one of the most diverse and productive ecosystems that provide direct and indirect benefits to millions of people worldwide [1-4]. In coral reefs, most biodiversity studies have focused on conspicuous organisms such as fish and macroinvertebrates, whereas the organisms that inhabit within the reef framework and that conform the coral reef cryptic fauna have received less attention [2,5]. This lack of knowledge occurs despite that cryptofauna represents most of the biodiversity in coral reefs, and that cryptic organisms play essential roles in the functioning of these ecosystems [2,5-7]. Therefore, changes in the cryptofauna community structure could also affect the ecosystem services that coral reefs provide [6-7].

Despite the important contributions of the cryptofauna to the biodiversity and function of coral reefs (i.e., food-web interactions, nutrient cycling), basic knowledge about their species richness and species composition, as well as of the factors that influence their community structure and function is still limited, particularly in the Eastern Tropical Pacific (ETP). In this region, few studies have systematically evaluated the responses of the 
cryptofauna to changes in the cover of the main substrate components in coral reefs, except for the research carried out by Enochs (2012) and Enochs and Manzello (2012) in Playa Larga Reef (Pacific of Panama). This lack of knowledge difficult our ability to evaluate the possible responses of coral reefs to natural and anthropogenic disturbances in the future [4, 6-9]. Here we evaluated how changes in coral cover could affect the species richness, abundance, and biomass of the motile cryptic invertebrates associated with dead coral and coral rubble in La Azufrada coral reef, ETP off Colombia.

\section{Methods}

\subsection{Study area}

This study was carried out in Isla Gorgona, a continental island located at $30 \mathrm{~km}$ off the Pacific coast of Colombia in the ETP $\left(2^{\circ} 58^{\prime} \mathrm{N}, 78^{\circ} 10^{\prime} \mathrm{W}\right.$; Figure 1$)$. The island belongs to the National Natural Park Gorgona where the most developed coral reefs of the Colombian Pacific can be found [10]. The weather in Isla Gorgona is tropical humid with a mean air temperature of $26^{\circ} \mathrm{C}$, a mean humidity of $90 \%$, and high precipitation levels $(\sim$ $6600 \mathrm{~mm}$ year $\left.^{-1}\right)$ [11]. Surface waters are warm $\left(25.1-27.5^{\circ} \mathrm{C}\right)$ and have low salinity $(26.2-$ 32.8), presenting low variability year-round [11-12].

In Isla Gorgona, the most developed coral communities and coral reefs are located on the eastern side of the island [10,13]. Among these, La Azufrada is the largest and continuous coral reef ( $9.4 \mathrm{ha}$ ), whose coral community is dominated by the branching coral Pocillopora damicornis [10,14].
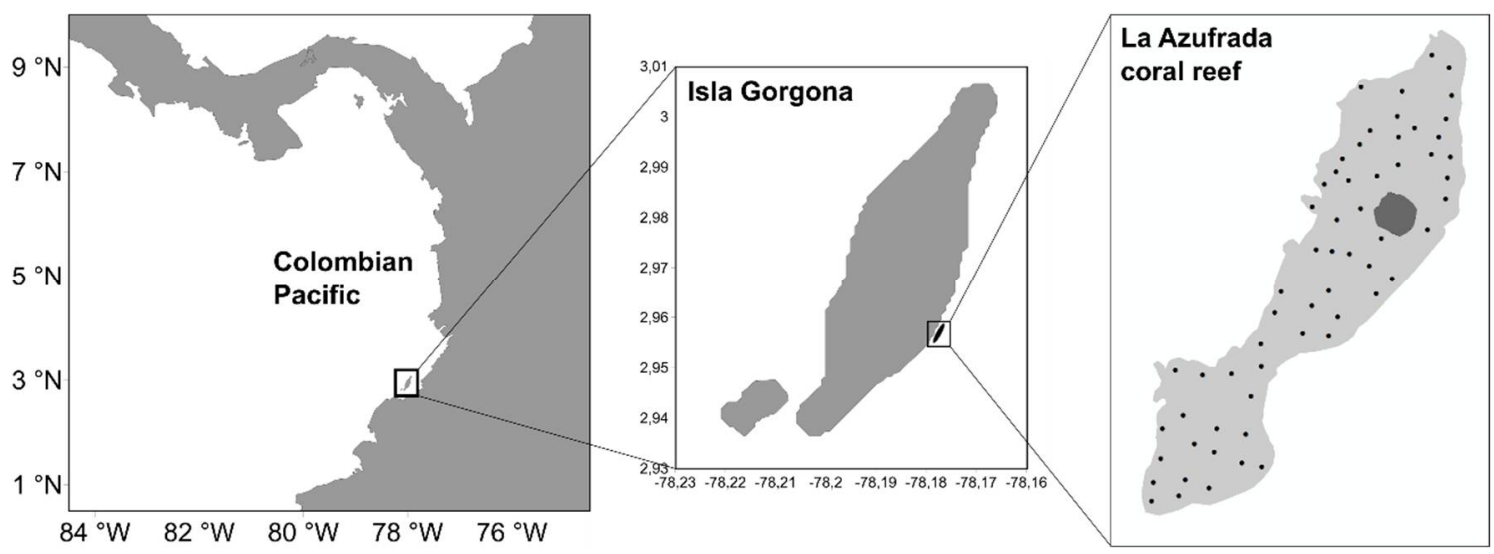

Figure 1. Map of La Azufrada coral reef in Isla Gorgona, Eastern Tropical Pacific off Colombia, indicating the sampling points where dead coral and coral rubble were collected.

\subsection{Field sampling}

Cryptofauna samples were collected during September 2019 at 60 sampling points covering the main substrate components of La Azufrada coral reef (Figure 1). At each sampling point, we placed a $1 \mathrm{~m}^{2}$ quadrat to characterize the substrate (subdivided in 50 $\mathrm{cm} \times 50 \mathrm{~cm}$ subquadrats), and four images were taken with an underwater digital camera in each subquadrat. Then, dead coral and coral rubble were collected within the quadrat by hand in an area of $30 \mathrm{~cm}$ by $30 \mathrm{~cm}\left(0.09 \mathrm{~m}^{2}\right)$ and were inmediately placed in plastic jars. Once in the laboratory of the field station, all the motile cryptic invertebrates were carefully sorted and stored in $96 \%$ ethanol until further processing.

\subsection{Data analyses}


Live coral cover in La Azufrada coral reef was evaluated using the program Coral Point Count [15]. For this, ten random points were located in each photo-quadrat, where the percentage of live coral cover was estimated (40 points in total per sampling point). Sampling points were grouped in four categories according to the live coral cover: $0-25 \%$, $25-50 \%, 50-75 \%$, and $75 \%-100 \%$.

In the case of the coral reef cryptofauna, all individuals were sorted in major taxonomic groups, and then identified to the lowest taxonomic level possible and counted. In addition, for each morphoespecies, organic biomass was estimated as the difference between dry-weight $\left(60^{\circ} \mathrm{C} \times 48\right.$ hours) and ash-free dry weight $\left(500^{\circ} \mathrm{C} \times 5\right.$ hours).

The estimated cryptofauna species richness was described by individual-based rarefaction curves using the program EstimateS, and the estimated species richness was calculated using the non-parametric richness estimator Chao 1 [16]. Differences in cryptofauna abundance and biomass between the four categories of live coral cover were evaluated by the non-parametric analysis of Kruskal-Wallis using R [17].

\section{Results}

\subsection{Cryptofauna species richness}

In the 60 sampling points analyzed across La Azufrada coral reef, we sorted 22153 motile cryptic invertebrates associated with dead coral and coral rubble, which belonged to 194 Operational Taxonomic Units (OTU) (Figure 2a). Among the taxa identified, crustaceans were the most diverse with $41 \%$ of the OTUs, followed by molluscans $(24 \%)$ and polychaetes $(22 \%)$. Contrary to our expectations, cryptofaunal OTU richness was similar in the four levels of coral cover analyzed, although according to the non-parametric richness estimator Chao 1, highest values occurred in the $25 \%-50 \%$ coral cover range (Figure $2 b$ ).

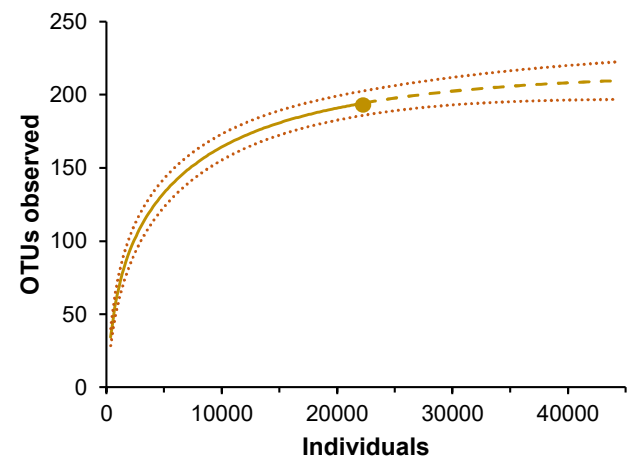

(a)

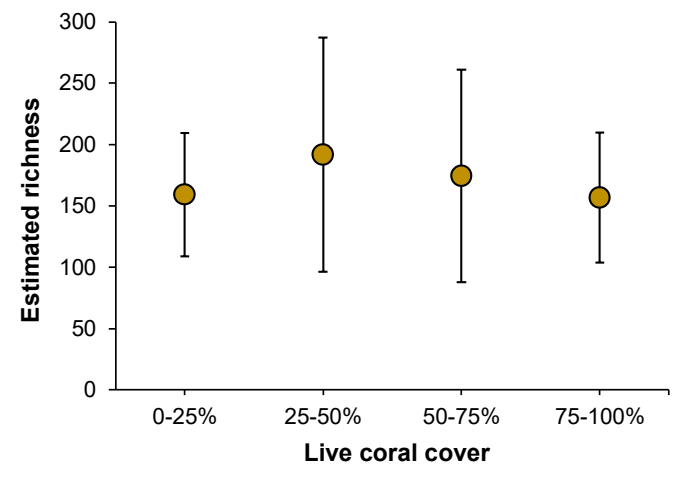

(b)

Figure 2. OTU richness of motile cryptic invertebrates associated with dead coral and coral rubble in La Azufrada coral reef, Colombian Pacific. (a) Individual-based rarefaction curve; (b) Estimated OTU richness by the non-parametric richness estimator Chao1 along a gradient of live coral cover. In (a) solid lines indicate the rarefied OTU richness, dashed lines indicate the extrapolated OTU richness, and the dot indicates the total OTUs observed. The 95\% confidence intervals are indicated as dotted lines in (a) or as error bars in (b). 
The abundance of the motile cryptic invertebrates associated with dead coral and coral rubble in La Azufrada coral reef was similar in the zones where coral cover ranged between zero and $75 \%(\mathrm{~K}-\mathrm{W}, \mathrm{p}>0.05)$, but was significantly lower where coral cover was the highest $(>75 \%$ coral cover; K-W and Dunn's-test, $\mathrm{p}<0.05)$ (Figure 3a). Cryptofauna abundance was mostly represented by crustaceans at the four zones analyzed $(47 \%)$, and their dominance increased in the zone with the highest coral cover ( $75 \%-100 \%$ coral cover) (Figure 3b). In contrast, the relative abundance of polychaetes was highest in the zones with the lowest coral cover ( $<25 \%$ coral cover), whereas the relative abundance of echinoderms was highest at the zones with intermediate coral cover (25-75\% coral cover) (Figure $3 b)$.

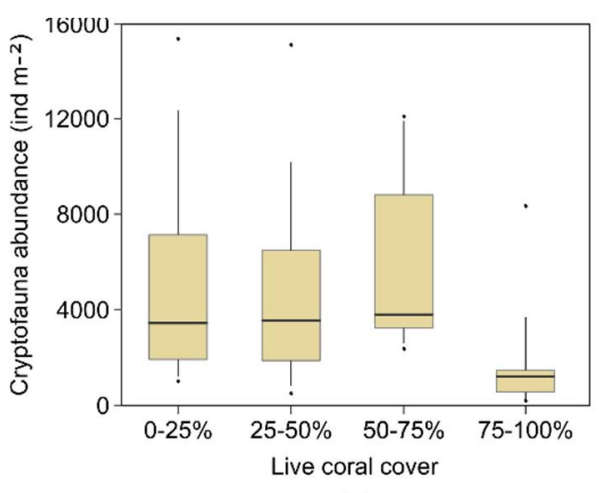

(a)

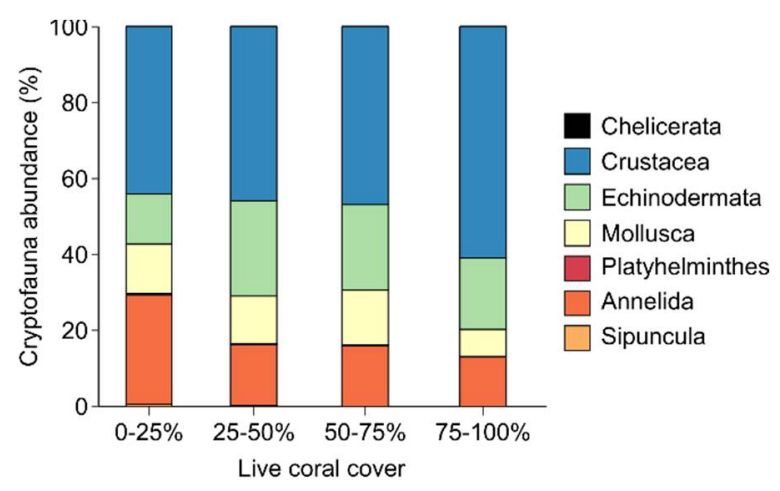

(b)

Figure 3. Abundance of motile cryptic invertebrates along a gradient of live coral cover in La Azufrada coral reef, Colombian Pacific. (a) Abundance per zone; (b) Relative contribution of the major taxonomic groups to the invertebrate abundance. The boxplot shows the median (horizontal line), the $25 \%$ and $75 \%$ percentiles (boxes), the $5 \%$ and $95 \%$ percentiles (whiskers), and outliers (dots).

The biomass of the motile cryptic invertebrates was similar among the four zones of coral cover analyzed $(\mathrm{K}-\mathrm{W}, \mathrm{p}>0.05)$, showing greater variability within each zone (Figure 4a). In contrast to cryptofauna abundance, biomass in the zones with coral cover between $25 \%-75 \%$ was mostly represented by echinoderms (53\%) (Figure $4 \mathrm{~b}$ ), mainly ophiuroids. In the zone with the lowest coral cover ( $<25 \%$ coral cover), both polychaetes and echinoderms represented most of the biomass (Figure $4 \mathrm{~b}$ ). The contribution of crustaceans to the cryptofauna biomass was considerably lower (Figure $4 \mathrm{~b}$ ), likely due to high abundances of small-bodied taxa (e.g., tanaidaceans and isopods) that have lower individual biomasses compared to large-bodied taxa such as some polychaetes (e.g, Amphinomidae) or ophiuroids. 


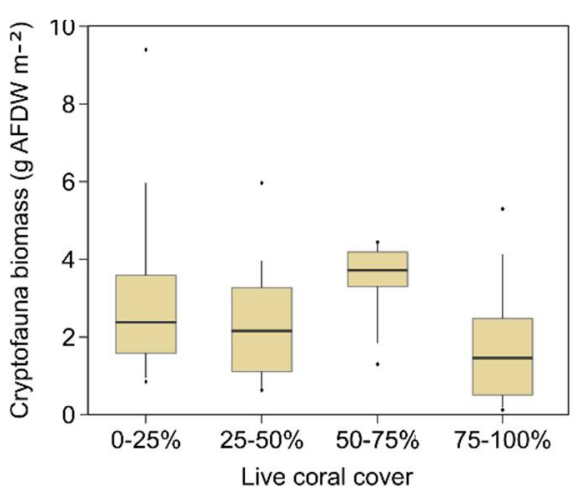

(a)

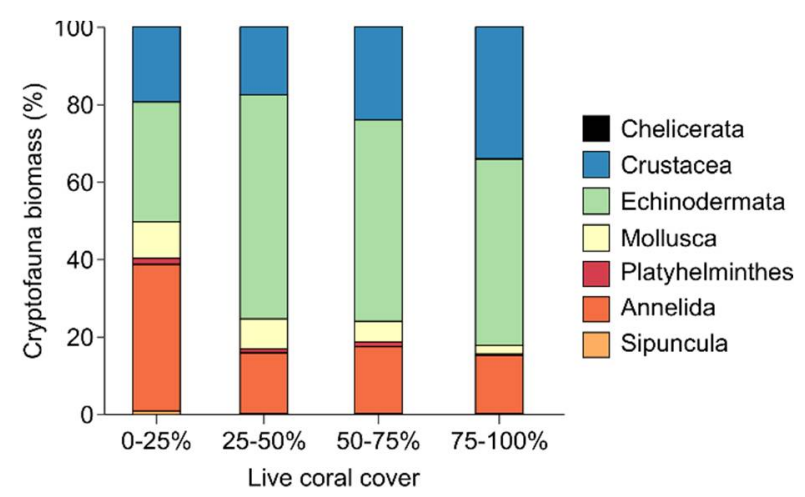

(b)

Figure 4. Biomass of motile cryptic invertebrates along a gradient of live coral cover in La Azufrada coral reef, Colombian Pacific (a) Biomass per zone; (b) Relative contribution of the major taxonomic groups to the invertebrate biomass.

\section{Conclusions}

The motile cryptic invertebrates associated with dead coral and coral rubble in $\mathrm{La}$ Azufrada coral reef was characterized by a great diversity of taxa, as has been documented in the ETP $[7,8]$ and other regions $[18,19]$. OTU richness and abundance was mostly represented by crustaceans, whereas echinoderms have higher contributions to the cryptofauna biomass. The highest contribution of crustaceans to cryptofauna species richness and abundance is a common characteristic in dead coral and coral rubble of reefs dominated by branching corals (e.g., Pocillopora, Acropora) in the eastern tropical $[7,8]$ and western subtropical Pacific [18], as well as in the Great Barrier Reef in Australia [19]. Contrary to our expectations, cryptofauna species richness and biomass were similar among the four levels of coral cover analyzed, whereas cryptofauna abundance was significanly lower only at the zones of the reef with the highest coral cover ( $>75 \%$ coral cover). Our results contrast with those documented by Enochs (2012) and Enochs and Manzello (2012) in Playa Larga Reef (Pacific of Panama), where the coral community structure is similar to La Azufrada. According to the authors, cryptofauna species richness is highest in the zones of the reef where coral rubble is most abundant and coral cover is lowest. Likewise, these authors found that cryptofauna abundance and biomass in Playa Larga are highest in the reef zones with intermediate levels of coral cover (20\%-80\%). Although methodological differences could partly explain the different results observed between Playa Larga in the Pacific of Panama [7-8] and La Azufrada in the Colombian Pacific, our results also highlight that even within a region (Panama Bight in the ETP), the cryptofauna community inhabiting similar structured coral reefs can show different responses to changes in the reef substrate, and likely to future disturbances. In the western subtropical Pacific, cryptofauna associated with coral rubble also have higher abundances at reefs with low coral cover [18]. In the Great Barrier Reef, cryptofauna abundance and biomass was highest in dead coral and coral rubble [19]. Our results also highlight the importance that the substrate heterogeneity has in the maintenance of the diversity and function in coral reefs, considering that the contribution of the different taxonomic groups to the species richness, abundance, and biomass vary across the range in coral cover.

Acknowledgments: We would like to thank Stephania Palacios, Juan Pablo Erazo, Alejandro Perlaza, Kevin Steven Mendoza, and Juan José Gallego for their help during the field trip. We specially thank Maria Alejandra Castillo, Santiago Castillo, Kevin Steven Mendoza, John Alexander Salazar, and Valentina Orozco for their help during the sorting, preliminary identification, and biomass analysis in the lab. We thank Edgardo Londoño and Juan Felipe Lazarus for their help with the identification of the invertebrates. We thank Parques Nacionales Naturales, specially the staff of PNN Gorgona for their logistical support. This study is part of the research project "Estructura y 
función de los invertebrados crípticos móviles en dos arrecifes coralinos del Pacífico colombiano" funded by COLCIENCIAS and Universidad del Valle to BV. This study was performed under the collection permit No. 009 of 2019.

Author Contributions: B.V. and A.G. conceived and designed the research; B.V. performed the laboratory analyses; B.V. analyzed the data; B.V. and A.G. wrote the paper.

Conflicts of Interest: The authors declare no conflict of interest.

\section{References}

1. Wilkinson, C.R. Global change and coral reefs: Impacts on reefs, economies and human cultures. Glob. Chang. Biol. 1996, 2, 547558.

2. Reaka-Kudla, M.L. The global biodiversity of coral reefs: A comparison with rain forests. Biodivers. II Underst. Prot. Our Biol. Resour. 1997, 2, 551.

3. Moberg, F.; Folke, C. Ecological goods and services of coral reef ecosystems. Ecol. Econ. 1999, 29, $215-233$.

4. Knowlton, N.; Brainard, R.E.; Fisher, R.; Moews, M.; Plaisance, L.; Caley, M.J. Coral reef biodiversity. In Life World's Oceans: Divers. Distrib. Abundance; Blackwell publishing: Hoboken, NJ, USA, 2010; pp. 65-74.

5. Gibson, R.; Atkinson, R.; Gordon, J.; Smith, I.; Hughes, D. Coral-associated invertebrates: Diversity, ecological importance and vulnerability to disturbance. Oceanogr. Mar. Biol. Annu. Rev. 2011, 49, 43-104.

6. Glynn, P.W.; Enochs, I.C. Invertebrates and their roles in coral reef ecosystems. In Coral Reefs: An Ecosystem in Transition; Springer: Dordrecht, The Netherlands, 2011; pp. 273-325.

7. Enochs, I.C. Motile cryptofauna associated with live and dead coral substrates: Implications for coral mortality and framework erosion. Mar. Biol. 2012, 159, 709-722.

8. Enochs, I.C.; Manzello, D.P. Responses of cryptofaunal species richness and trophic potential to coral reef habitat degradation. Diversity 2012, 4, 94-104.

9. Harborne, A.R.; Rogers, A.; Bozec, Y.M.; Mumby, P.J. I Multiple stressors and the functioning of coral reefs. Annu. Rev. Mar. Sci. 2017, 9, 445-468.

10. Zapata, F.A. Formaciones coralinas de Isla Gorgona. In Gorgona Marina: Contribución al Conocimiento de Una Isla Única, INVEMAR: Santa Marta, Colombia, 2001; Volume 7, pp. 41-50.

11. Díaz, J.M.; Pinzón, J.H.; Perdomo, A.M.; Barrios, L.M.; López-Victoria, M. Generalidades. In Gorgona Marina: Contribución al Conocimiento de Una Isla Única; INVEMAR: Santa Marta, Colombia, 2001, Volume 1, pp. 17-26.

12. Giraldo, A.; Rodríguez-Rubio, E.; Zapata, F.A. Condiciones oceanográficas en isla Gorgona, Pacífico oriental tropical de Colombia. Lat. Am. J. Aquat. Res. 2008, 36, 121-128.

13. Glynn, P.W.; von. Prahl, H.; Guhl, F. Coral reefs of Gorgona Island, Colombia, with special reference to corallivores and their influence on community structure and reef development. Boletín De Investig. Mar. Y Costeras 1982, 12, $185-214$.

14. Zapata, F.A.; Vargas-Ángel, B. Corals and coral reefs of the Pacific coast of Colombia. In Latin American Coral Reefs, Elsevier: Heredia, Costa Rica, 2003, pp. 419-447.

15. Kohler, K.E.; Gill, S.M. Coral Point Count with Excel Extensions (CPCe): A visual basic program for the determination of coral and substrate coverage using random point count methodology. Comput. Geosci. 2006, 32, 1259-1269.

16. Colwell, R.K. EstimateS: Statistical Estimation of Species Richness and Shared Species from Samples. Version 9. 2013. User's Guide and application. Available online: http://purl.oclc.org/estimates (accessed on).

17. RStudio Team. RStudio: Integrated Development for R. 2020. Available online: http://www.rstudio.com/ (accessed on).

18. Biondi, P.; Masucci, G.D.; Reimer, J.D. Coral cover and rubble cryptofauna abundance and diversity at outplanted reefs in Okinawa, Japan. PeerJ 2020, 8, e9185.

19. Kramer, M.J.; Bellwood, D.R.; Bellwood, O. Benthic Crustacea on coral reefs: a quantitative survey. Marine Ecology Progress Series $\underline{2014,511,105-116 .}$ 